\title{
INTERNET USE FOR INSTRUMENTAL PURPOSES IN RELATION TO THE QUALITY OF LIFE AMONG ELDERLY FEMALES AND MALES IN POLAND - MEDIATING EFFECTS OF LONELINESS AND SOCIAL SUPPORT
}

\section{GRZEGORZ WÓJCIK ${ }^{1}$, KAROLINA KNIAZIUK ${ }^{1}$, KATARZYNA ZAWISZA ${ }^{1}$, BEATA TOBIASZ-ADAMCZYK ${ }^{1}$, and TOMASZ GRODZICKI ${ }^{2}$}

Jagiellonian University Medical College, Kraków, Poland

${ }^{1}$ Department of Medical Sociology, Chair of Epidemiology and Preventive Medicine

${ }^{2}$ Chair of Internal Medicine and Gerontology

\begin{abstract}
Objectives: The study explores the direct and indirect associations (i.e., through the extent of the level of loneliness and perceived social support) between internet use for instrumental purposes and the quality of life (QoL) among elderly females and males in Poland. Material and Methods: The analysis was based on 2001 face-to-face interviews performed among randomly selected individuals aged $\geq 65$ years from the general population. The collected data was weighted to generalize the study sample for the reference population. The analysis was conducted using multiple linear regression models. The mediation effect was tested according to the Baron and Kenny approach. Results: The obtained results indicate that internet use for instrumental purposes is directly related to a better QoL of elderly Polish males. This positive effect among men also occurs indirectly, through the decrease in loneliness levels as well as the increase in social support scores. It has also been shown that among elderly females, the effect of internet use for instrumental purposes is not related to a better QoL, either directly or indirectly. Conclusions: Internet use for instrumental purposes seems to be important in enhancing a successful life among elderly male adults. However, these technologies are not associated with better QoL among females. Practitioners should be aware of these gender differences. The study adds to the previous studies by demonstrating that the feeling of loneliness and social support mediates the relationship between internet use for instrumental purposes and QoL among elderly males, whereas among elderly females this effect does not occur. Int J Occup Med Environ Health. 2022;35(2):169-85
\end{abstract}

Key words:

quality of life, social support, loneliness, internet use, gender-related differences, Polish elderly population

Funding: this research was supported by the National Science Centre, Poland (OPUS grant No. 2014/13/B/NZ7/02300, entitled "Elder neglect and self-neglect - challenges for formal and informal caregivers and medical and social professional care system," project manager: Prof. Tomasz Grodzicki).

Received: January 3, 2021. Accepted: July 13, 2021.

Corresponding author: Grzegorz Wójcik, Jagiellonian University Medical College, Department of Medical Sociology, Chair of Epidemiology and Preventive Medicine, Kopernika 7a, 31-034 Kraków, Poland (e-mail: grzegorz.wojcik@uj.edu.pl). 


\section{INTRODUCTION}

A growing consensus exists among researchers that the current Western societies are undergoing 2 far-reaching social processes. Firstly, population aging is related to the increasing proportion of elderly populations among societies [1,2]. By 2050, 1 in 4 people living in Europe and Northern America may be aged $\geq 65$ years; in Poland, at the same time, people aged $\geq 60$ years will account for $40 \%$ of the whole population $[3,4]$. The second phenomenon - digitalization - is characterized by diffusion dynamics through the use of information and communication technology (ICT) in almost every aspect of everyday life [5].

Regarding the latter, specific population segments, such as elderly adults, could be excluded from using new technologies because of limitations due to the natural process of aging with regard to the detriment of their listening, vision and motor skills [6]. Another important reason is the digital divide. Numerous projects state that the digital divide occurs between cohort groups, stressing that the digital level of internet use among the elderly population is much lower compared to the younger ones [7].

In Poland, elderly people ( $\geq 65$ years old) are considered as a group that uses the internet less often compared to younger cohorts. The report prepared by Statistics Poland and the Statistical Office in Łódź showed that the use of the internet almost every day was declared by only $13 \%$ of Poles above the age of 65 , compared to $53 \%$ of the general population. Elderly Polish adults used the internet in order to, firstly, seek information (16\%) and, secondly, for online banking (9\%) [4]. There are no studies which have examined the correlations between internet use and the quality of life (QoL) and gender among the Polish elderly population.

Elderly people represent a segment that should confront the use of new technologies at this point of time mainly because of their positive impact on their social and economic welfare and QoL [8]. Various definitions of QoL have been developed over the past decades, and a significant evolution from objective to subjective indicators has been observed. In the current study, the authors decided to use the definition of QoL established by the World Health Organization (WHO) which described it as an "individuals' perception of their position in life in the context of the culture and value systems in which they live and in relation to their goals, expectations, standards and concerns" [9].

It is widely accepted that internet use impacts on the QoL of elderly adults. As an integral part of the environment, information and communication technology may both facilitate and/or hinder elderly people in engaging in daily occupations and, consequently, raise or decline their QoL. Different studies highlight the positive impact of internet use by the elderly on their QoL [10]. It could be stated that internet users scored significantly higher than elderly non-users on measures of personal growth and purpose in life [11]. More specifically, internet use may increase QoL by facilitating social interactions and communication with family and friends, enabling social involvement, as well as providing various forms of entertainment [12]. What is more, the internet offers a range of other consumer services, such as online banking which enables elderly adults to overcome physical handicaps and stay independent. Consequently, for those elderly people who experience physical limitations, online activities related to financial matters contribute to QoL and help to cope with this group's typical mental and physical difficulties [10]. On the other hand, some researchers have found that internet use was not related to either depression symptoms or well-being in the elderly population [13].

Current research has shown that elderly adults engage with the digital world for different purposes including banking issues, work, seeking information, and entertainment [14]. In this study, the authors decided to focus especially on the relationship between internet use for instrumental purposes, such as online banking, and QoL among elderly Polish females and males. As Campbell 
and Kwak [15] stated, instrumental uses of ICT mean obtaining useful information or using services such as online banking without direct interaction with others.

In a study conducted by van Boekel et al. [16] on the ICT practices of elderly adults (aged 65+), 4 groups of internet users were identified: practical users (engaging in functional activities, e.g., banking issues), minimizers (low frequency use for email and information search), maximizers (high-frequency use for a range of purposes), and social users (communicating with friends and family). Practical users and maximizers reported the highest level of psychological well-being which suggests that wellbeing of elderly adults might be influenced by different purposes of internet use.

With regard to the relationship between internet use and loneliness in later life, the scope of the studies demonstrated its negative association. Internet use decreases the level of loneliness because it enables digital socializing, gaining social support and engaging in activities of interest [17]. Loneliness has been examined as a potential mediator between internet use and well-being among elderly adults as well. In the research conducted by Heo et al. [11], internet use predicted higher social support, leading to lower levels of loneliness and higher levels of psychological well-being. In turn, Sum et al. [18] demonstrated that elderly adults' use of the internet, especially for communication with relatives and friends, was associated with lower levels of loneliness.

Social support has been found as a significant factor to the elderly people's QoL. Various researchers emphasized the importance of internet use for enhancing a better QoL of the elderly population stressing that using it has been associated with the increased social connectivity, the enrichment of isolated elderly people as well as lower life stress $[17,19]$. Nevertheless, with regard to the relationship between instrumental use of the internet and social involvement, results of the studies are inconsistent. As Ihm and Hsieh reported [20], instrumental uses of ICT predicted more involvement in social activities among elderly adults, whereas according to Choi and DiNitto's study [21], internet use for instrumental tasks, such as shopping and banking, was negatively associated with community engagement.

\section{Aim}

The aim of this study was to analyze the direct and indirect associations (i.e., through the extent of the levels of loneliness and social support) between the instrumental use of the internet among elderly females and males in Poland. In their study, the authors focused on elderly women and men separately, whereas a common research practice too often considers them as a homogeneous group [11,17]. Based upon existing research, it is not clear whether internet use for instrumental purposes impacts on the QoL of elderly females and males in the same way. Secondly, the authors examined 2 potential mechanisms - loneliness and social support - through which the instrumental use of the internet might promote the QoL in elderly women and men. Specifically, the current study addressed the following 2 research questions:

1. Is the use of the internet for instrumental purposes directly associated with the QoL among elderly Polish females and males?

2. Is the use of the internet for instrumental purposes associated with a decreased feeling of loneliness and a greater perception of social support, which are indirectly related to a greater QoL among elderly Polish females and males?

\section{MATERIAL AND METHODS Sample}

A cross-sectional study: "Elder neglect and self-neglect - challenges for formal and informal caregivers and the medical and social professional care system" was conducted in the Małopolska Region in 2017. The total study sample included 2894 face-to-face interviews: 2001 with randomly selected community-dwelling individuals from 


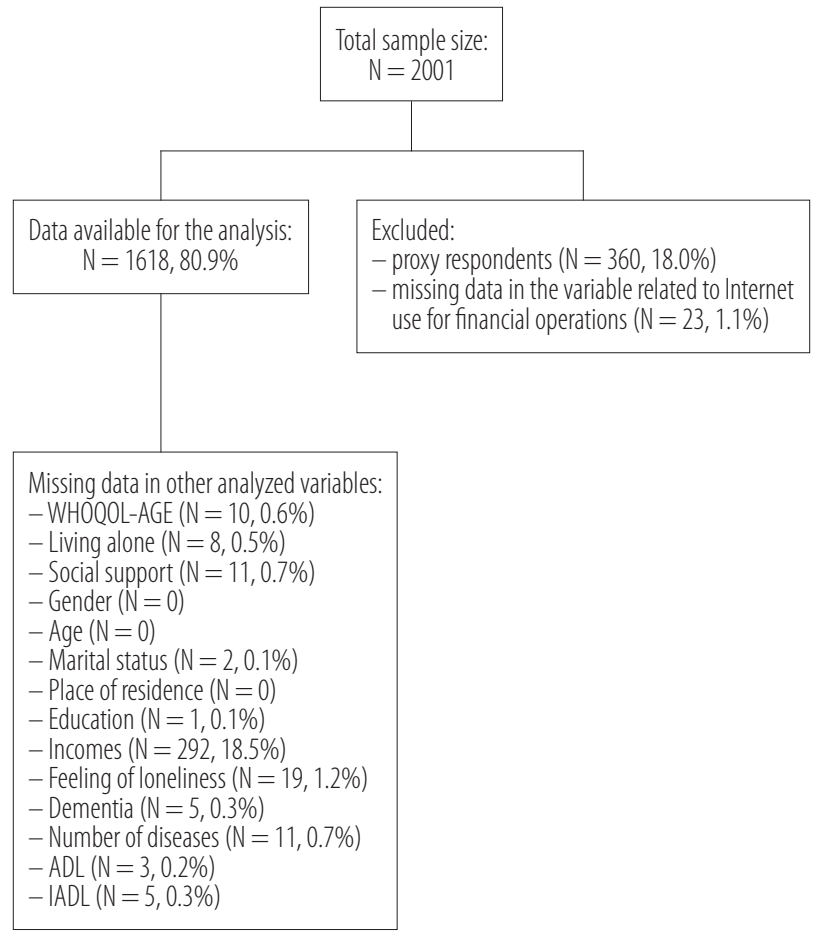

ADL - Activity of Daily Living; IADL - Instrumental Activity of Daily Living; WHOQOL-AGE - The World Health Organization Quality Of Life - Age.

Figure 1. The selection of participants in a cross-sectional study on the associations between Internet use for instrumental purposes and the quality of life $(\mathrm{Q} \mathrm{oL})$ among elderly Polish females and males, 2017, the Małopolska Region, Poland

among the general population, 308 with social service users and 585 with hospital patients. The analysis was based on 1618 interviews performed among individuals aged $\geq 65$ years, selected from the general population. The sample available for the analysis is described in Figure 1. The data were weighted to generalize the study sample to the reference population. The study was approved by the Bioethics Committee, Jagiellonian University, Kraków, Poland (decision No. 122.6120.19.2015). Written informed consent was obtained from each participant.

\section{Measures}

The quality of life

The quality of life was measured by the Polish version of 13-item World Health Organization Quality Of Life - Age
(WHOQOL-AGE) scale. The tool contains items from the EUROHIS-QOL (related to the following domains of QoL: physical, psychological, social relationships and environment) and the WHOQOL-OLD (items related to sensory abilities, autonomy, past, present and future abilities, social participation and intimacy) scales [22]. The final score ranged $0-100 \mathrm{pts}$, and a higher score is interpreted as a better QoL [23].

Internet use for instrumental purposes

Internet use for instrumental purposes evaluated whether the respondents used the computer for financial operations $(0-$ no, 1 - yes).

\section{Loneliness}

The De Jong Gierveld Loneliness Scale consisting of 11 items was used to assess emotional and social loneliness [24]. Emotional loneliness is the lack of a specific, intimate relationship, and social loneliness is a lack of social integration. The respondents answered each item using a 5-point scale ranging from "definitely yes" to "definitely no." The final score ranged 0-100 pts. Higher scores indicated a higher level of loneliness.

\section{Social support}

The perceived social support was measured by the OSLO-3 Social Support Scale [25]. It consists of 3 items that ask for the number of close confidants, the sense of concern from other people, and the relationship with neighbors with a focus on the accessibility of practical help. The total score ranged 0-100 pts, with high values representing strong levels and low values representing poor levels of social support.

\section{Possible covariates considered}

Demographic and socio-economic variables

Data were collected on: gender ( 0 - male, 1 - female), age (in years), place of residence ( 1 - rural area, 2 - town 
$\leq 200000$ residents, 3 - city $>200000$ residents), marital status ( 1 - never married, 2 - married, 3 - widowed, 4 divorced), education level (1 - primary or lower, 2 - vocational, 3 - high school, 4 - university degree or higher), personal net monthly income ( 1 - lower than the median, 2 - equal or larger than the median), and living alone (0 no, 1 - yes).

\section{Health-related variables}

The Katz Scale of Independence in Activities of Daily Living (ADL) [26] was used to evaluate a respondent's ability to perform ADL independently. It measures items such as bathing, dressing, toileting, transferring (moving in or out of a chair or a bed), continence, and feeding. The final score ranged 0-6 pts. To appraise the complex activities of daily living, the Lawton Scale of Instrumental Activities of Daily Living (IADL) was used [27]. It involves using a phone, reaching places beyond walking distance, shopping, preparing meals, doing housework, doing the washing up, preparing and taking medications, and managing money. The final score ranged 8-24 pts. The total number of diseases was estimated based on self-reported data on the prevalence of 25 various conditions. The respondents were considered to have a disease if they reported being ever diagnosed with the disease and they suffered from the disease during the past 12 months. The minimum score was 0 and the maximum score was 14 . Additionally, dementia was analyzed separately ( $1-$ is ill, $2-$ is not ill).

\section{Statistical analysis}

In order to find differences in the considered variables between gender and internet use for instrumental purposes, Pearson's $\chi^{2}$ tests were performed for factorial variables and Mann-Whitney $U$ tests for the continuous ones. A linear regression model was conducted to analyze the association between internet use and QoL. Afterwards, the model with interaction was used to assess

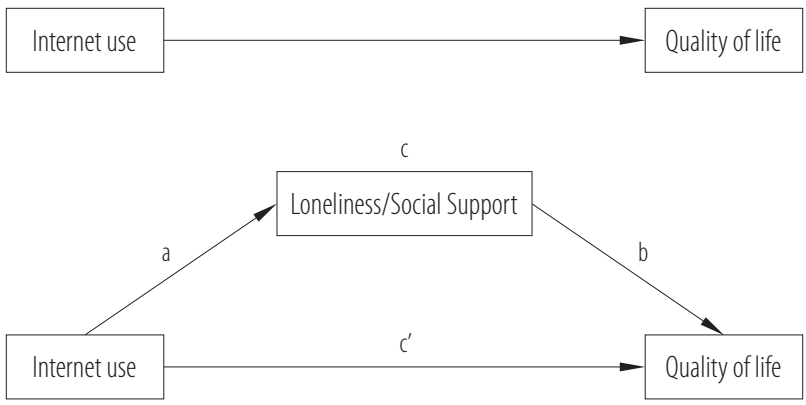

Figure 2. The mediating models depicting the total effect of Internet use for instrumental purposes on the independent variable predicting the mediator (a), the mediator predicting the dependent variable (b), the quality of life (c), the direct effect of Internet use for instrumental purposes on the quality of life after including the mediator $\left(c^{\prime}\right)$, in a cross-sectional study among elderly Polish females and males, 2017, the Małopolska Region, Poland

the moderation effect of gender. Then, to evaluate differences between the gender groups, the linear regression models for each group were performed. An analogous analysis for internet use for instrumental purposes and the loneliness/social support relationship was performed.

The mediation role of loneliness and social support for instrumental use of the internet and the QoL relationships of men and women was assessed. Four paths were considered: path a - independent variable predicting the mediator, path $b$ - mediator predicting the dependent variable, path $\mathrm{c}$ - independent variable predicting the dependent variable, and path c' - path c after including the mediator (Figure 2). The Sobel test of the indirect effect to assess the significance of the mediation effect was used. Finally, the Wald test for verifying the group difference in the indirect effect between men and women was performed.

All the analyses were conducted in the following steps:

1. A model adjusted for age.

2. A model adjusted for age, gender, education level, marital status, place of residence and monthly incomes.

3. A model from step 2, adjusted for ADL, IADL, dementia and the number of diseases. 
4. A model from step 3, adjusted for living alone and loneliness (with the exception of those models where loneliness was a dependent variable).

Analyses were conducted with SPSS 25 and Mplus Base Program v. 7.0. The adopted level of significance was 0.05 .

\section{RESULTS}

\section{Sample characteristics}

Table 1 shows that women accounted for the majority of the elderly Polish population (62.0\%) and were mostly widowed (53.4\%). They also had mainly primary education (46.3\%) and lived in an urban area (51.3\%). Nearly $34 \%$ of them lived alone and had, on average, 3 diseases. Their personal net monthly incomes amounted to PLN 1250. Men represented $38.0 \%$ of the population and mainly lived in a rural area (51.1\%). Most of them were married (74.7\%), had vocational education (41.9\%), just approx. 15\% of them lived alone and usually suffered from 2 diseases. They also earned more (PLN 1750) and had a higher score of QoL than women (68.1 vs. 65.3). Finally, men were more likely to use the internet for instrumental purposes than women (18.4\% vs. $7.2 \%)$.

The comparison of elderly women and men who used the internet vs. those who did not use it for financial operations is presented in Table 2. The majority of users in both gender groups were younger (median values: 70 years vs. 76 years among females, and 70 years vs. 74 years among males) more likely married (60.8\% vs. $36.6 \%$ among females, $88.2 \%$ vs. $71.6 \%$ among males), and had a university degree or higher $(51.4 \%$ vs. $8.7 \%$ in women, 48.5 vs. 6.2 in men). Additionally, male nonusers reported an increased feeling of loneliness (median values: 31.7 vs. 24.2) and lower levels of social support (median values: 63.6 vs. 81.8 ). Both women and men who did not use the internet for instrumental purposes indicated lower QoL (median values: 61.6 vs. 67.9 in women, 65.2 vs. 67.9 in men), compared with the users.

\section{The instrumental use of the internet -} QoL relationship

The results showed that gender moderated the relationship between the instrumental use of the internet and QoL ( $\mathrm{p}<0.05$ for all models). The results for the female group showed that there was no significant association between the discussed variables. For men, the results indicated that the internet use for instrumental purposes was associated with a higher score of QoL ( $\mathrm{B}=7.48, \mathrm{p}<0.001$ in the model controlling for socio-economic and health-related characteristics) (Table 3, Figure 3).

\section{The instrumental use of the internet and loneliness relationship among elderly females and males}

The analysis of interaction displayed the moderation effect of gender on loneliness. A further analysis showed that using the internet for instrumental purposes was associated with a decreased feeling of loneliness only among men $(B=-8.95, p<0.001$ in the fully adjusted model) (Table 3).

\section{The mediating effect of loneliness on the instrumental use of the internet - QoL relationship}

For women, the models did not meet the objectives, (path a was not significant). Therefore, loneliness was not found as a mediator in this group. For men, the results indicated a significant total direct effect (path c) of the instrumental use of the internet on QoL ( $\mathrm{B}=12.94, \mathrm{p}<0.001)$, a significant direct effect (path $\left.c^{\prime}\right)(B=7.66, p=0.002)$, and a significant indirect effect through loneliness $(\mathrm{B}=5.28$, $\mathrm{p}<0.001)$. The outcomes also showed that internet use for instrumental purposes was associated among males with lower loneliness scores $(B=-8.30, p<0.001)$, and loneliness was negatively associated with $\mathrm{QoL}(\mathrm{B}=-0.64$, $\mathrm{p}<0.001)$. The Wald test indicated that the difference 
between the indirect effects for gender groups was significant only for the second (controlled for socio-demographic variables) and third model (controlled for sociodemographic and health-related variables) (Table 4).

\section{The instrumental use of the internet and social support relationship among elderly females and males}

The moderation effect of gender on social support was found. The results revealed that the instrumental use of the internet was associated among elderly males (but not females) with higher social support scores ( $B=5.60$, $\mathrm{p}<0.001$ in the fully adjusted model) among elderly males, but not among females (Table 3).

\section{The mediating effect of social support on the instrumental use of the internet - QoL relationship}

Models for females did not show the mediating effect (path a was not significant). For males, the outcomes revealed a significant total direct effect (path c) of the instrumental use of the internet on QoL $(B=12.93$, $p<0.001)$, a significant direct effect (path c') $(B=7.99$, $\mathrm{p}<0.001)$ and a significant indirect effect through social support $(B=4.95, p<0.001)$. The results also indicated that internet use for instrumental purposes among males was associated with higher social support scores ( $\mathrm{B}=11.90, \mathrm{p}<0.001)$, and social support was positively associated with QoL $(B=0.42, \mathrm{p}<0.001)$. A significant indirect effect was noted through all considered models. The Wald test showed that the difference between the indirect effects for the discussed groups was significant for all models (Table 4).

\section{DISCUSSION}

The purpose of the present study was to explore whether the instrumental use of the internet is directly associated with the QoL among elderly Polish females and males.
Apart from that, the authors' aims were to examine the indirect relations, i.e., through the extent of the level of loneliness and social support between internet use for instrumental purposes and QoL with regard to gender of elderly adults.

Concerning the first aim, it could be stated that the instrumental use of the internet is directly associated with a better QoL among elderly men, but this relationship is not valid for women. This finding could be explained by referring to the previous study which indicated different ways of internet use among elderly females and males [16]. In line with this study, elderly men were more often characterized as practical users of ICT, who are engaged in functional activities, such as online banking or searching for information, whereas elderly females mainly used the internet for social and leisure-related activities. The use of technology, such as the internet, may help raise the levels of the QoL of elderly males, who face declining opportunities due to physical limitations for staying independent. Due to internet use, elderly men still hold control over their financial matters which contributes to their better well-being and the overall QoL [10].

Moreover, according to a study by Van Boekel et al. [16], the psychological well-being of practical users of the internet, as has been reported, was significantly higher compared with that of social users. Consequently, elderly males perceive the instrumental use of the internet as more valuable compared with females which, in turn, could influence their QoL. According to Helsper [28], offline gender roles influence online behavior; therefore, these findings are consistent with traditional societal expectations towards each gender suggesting that among elderly adults, the instrumental use of the internet is a male-dominated activity.

Referring to the socio-demographic characteristics, internet use for instrumental purposes was prevalent among holders of university diplomas, people living in bigger cities and those with higher monthly income. These findings are 


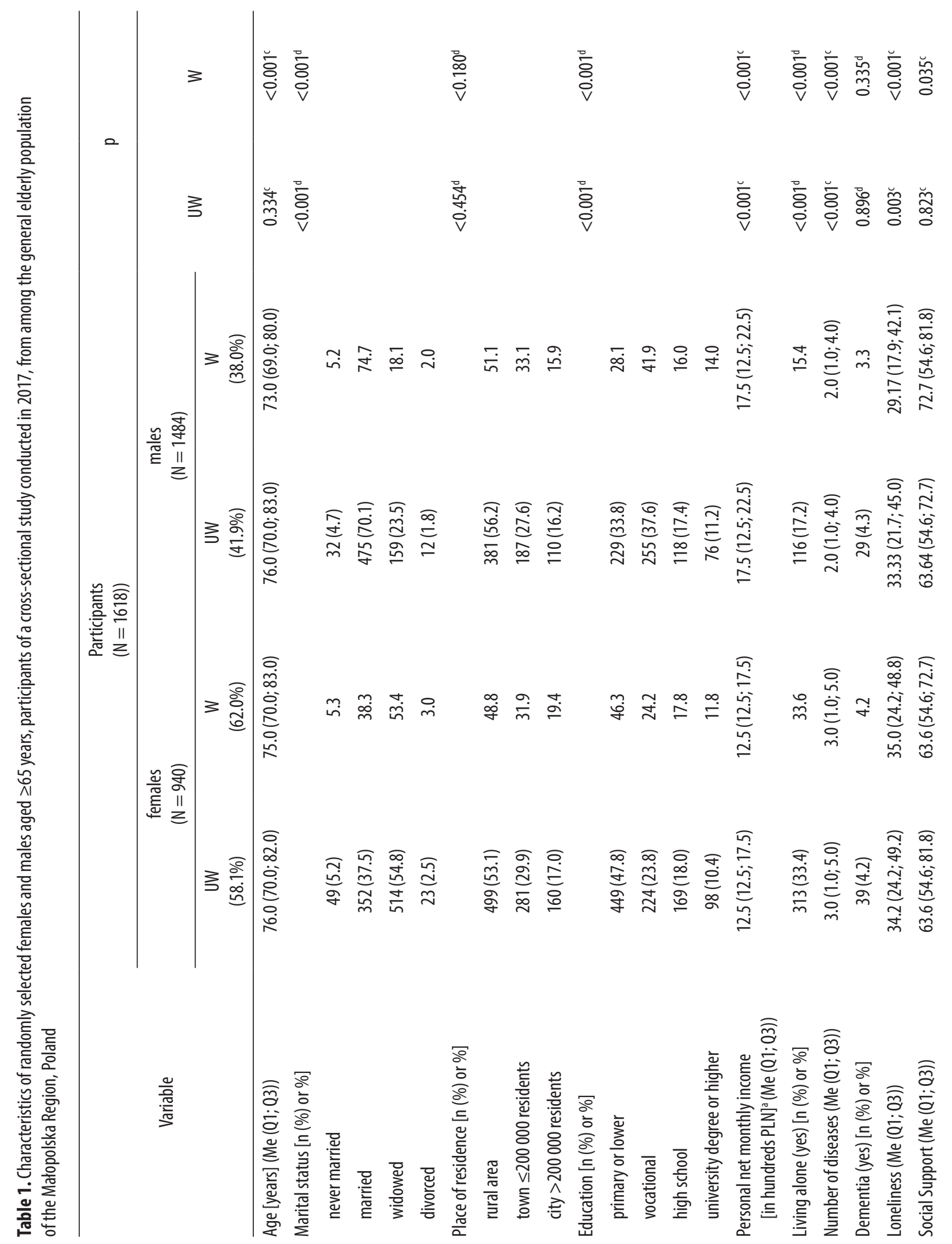




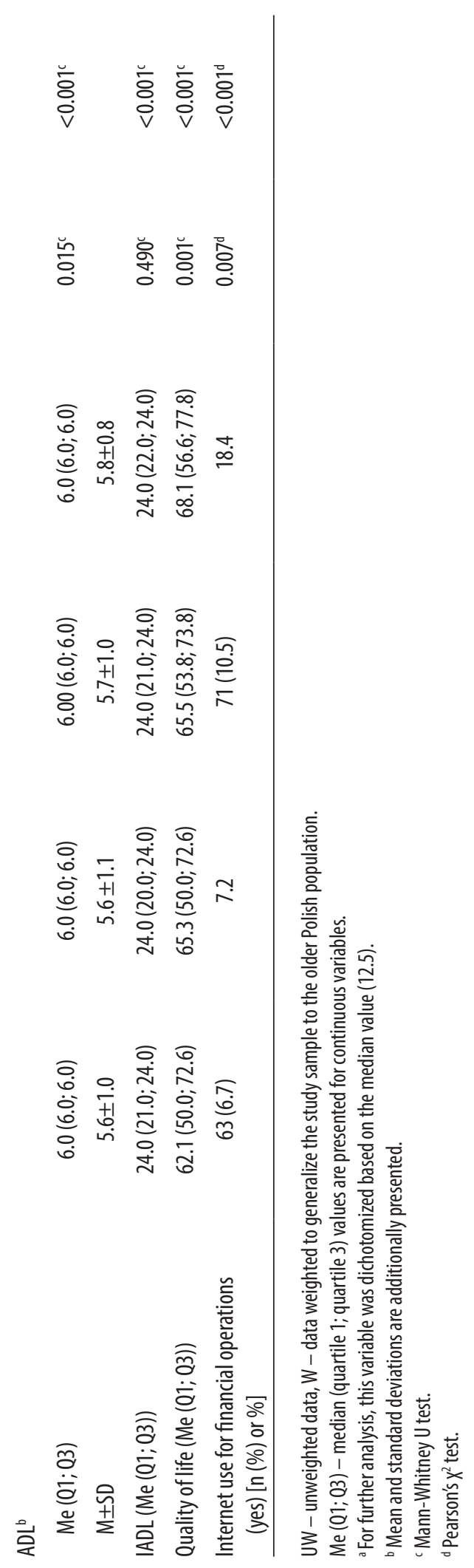

in line with the previous study which confirmed that elderly adults who use the internet for instrumental activities are more likely to be younger, and to have higher income [20]. Additionally, these results suggest that the socio-economic status could be the most important predictor of a digital exclusion as those groups who are disadvantaged in a traditional socio-economic sense were found to be most at risk of exclusion from the digital technology [28].

Regarding the second aim, i.e., the relationship between the instrumental use of the internet and QoL through the feeling of loneliness and perception of social support (mediating effects), the authors found a significant association for males, but not for females. In other words, the use of the internet for instrumental purposes predicts a lower loneliness level and higher perception of social support among males, which in turn predicts their better QoL. For elderly Polish females, the instrumental use of the internet is not a protective factor against loneliness, it is not associated with higher social support and, consequently, it is not significantly related to the perceived QoL. The plausible explanation for these findings could be provided by the gender role theory. Men transitioned to retirement are forced to renegotiate their status in terms of masculinity as their physical strength is decreasing, their position within the society becomes lower, and the loss of power accompanies such an altered status [29]. Thus, for instance, the capability of online banking services use could serve as a compensation, at least to some extent, for the afore-mentioned changes, indicating that they still hold control over their lives. Moreover, as was assumed, internet use for instrumental purposes reinforces the self-confidence and self-efficacy of elderly males and, consequently, contributes to their QoL as they perceive themselves to be still active in social reality [30].

With regard to the relationship between internet use for instrumental purposes and lower levels of loneliness among elderly males, it is argued that online financial ac- 


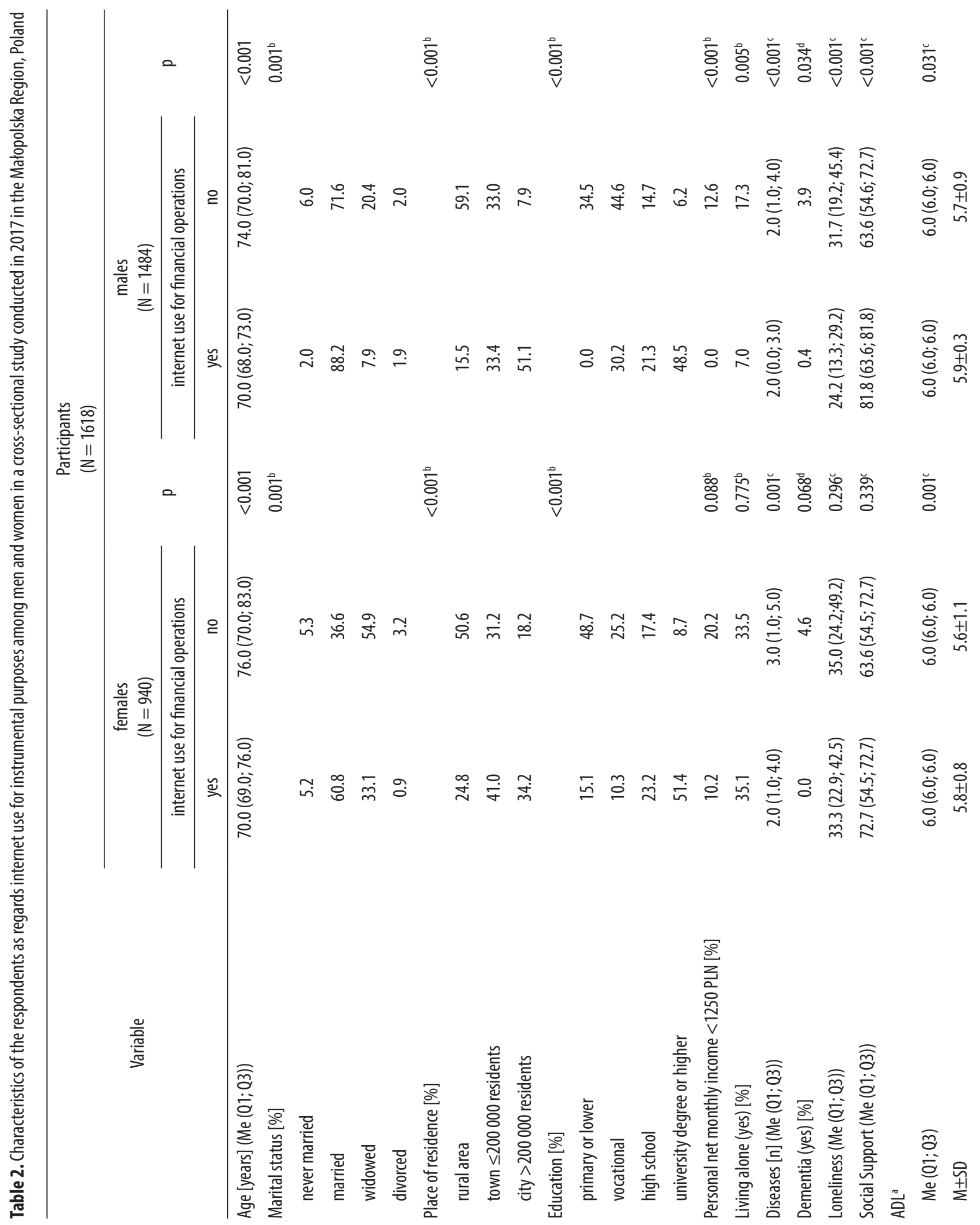




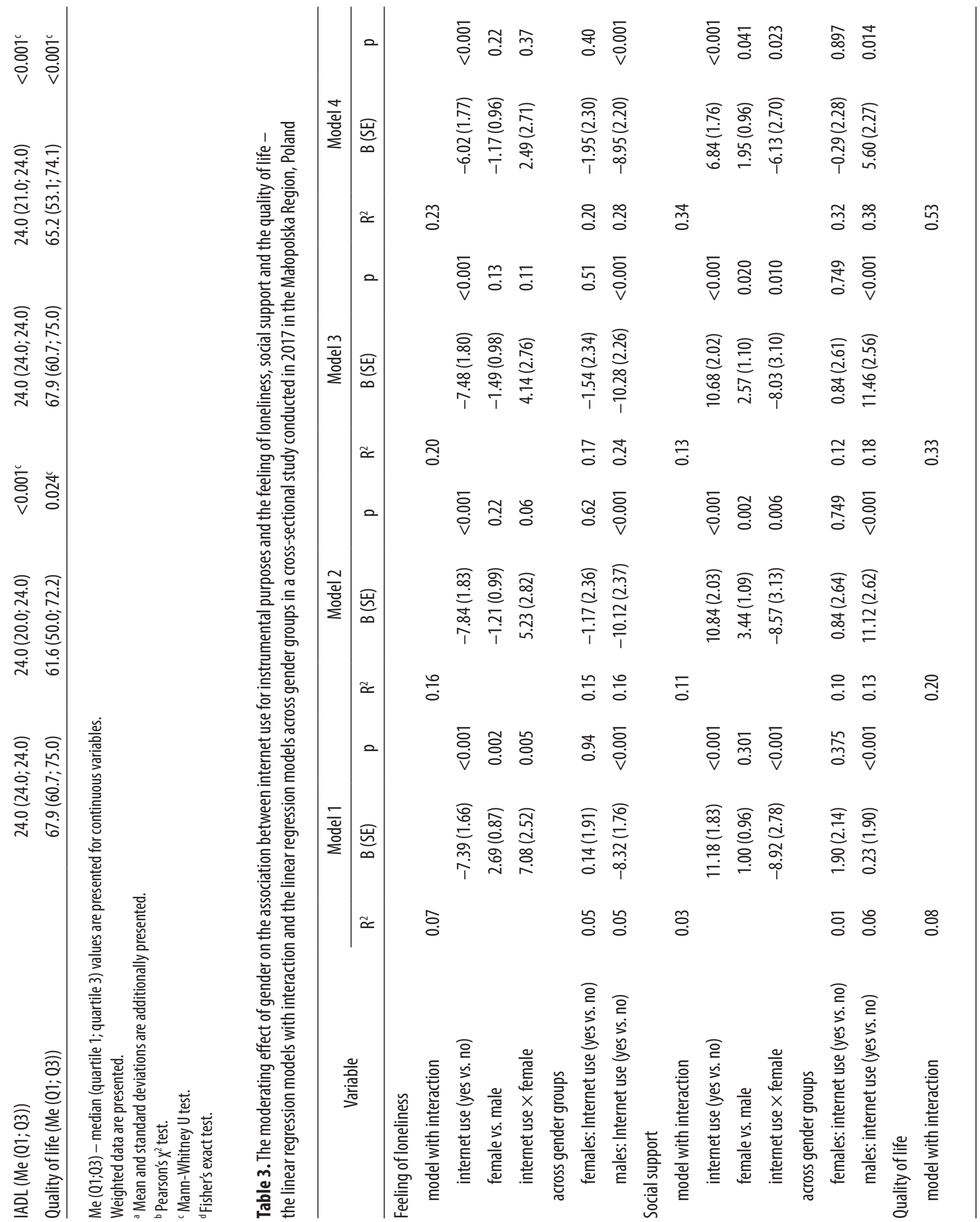




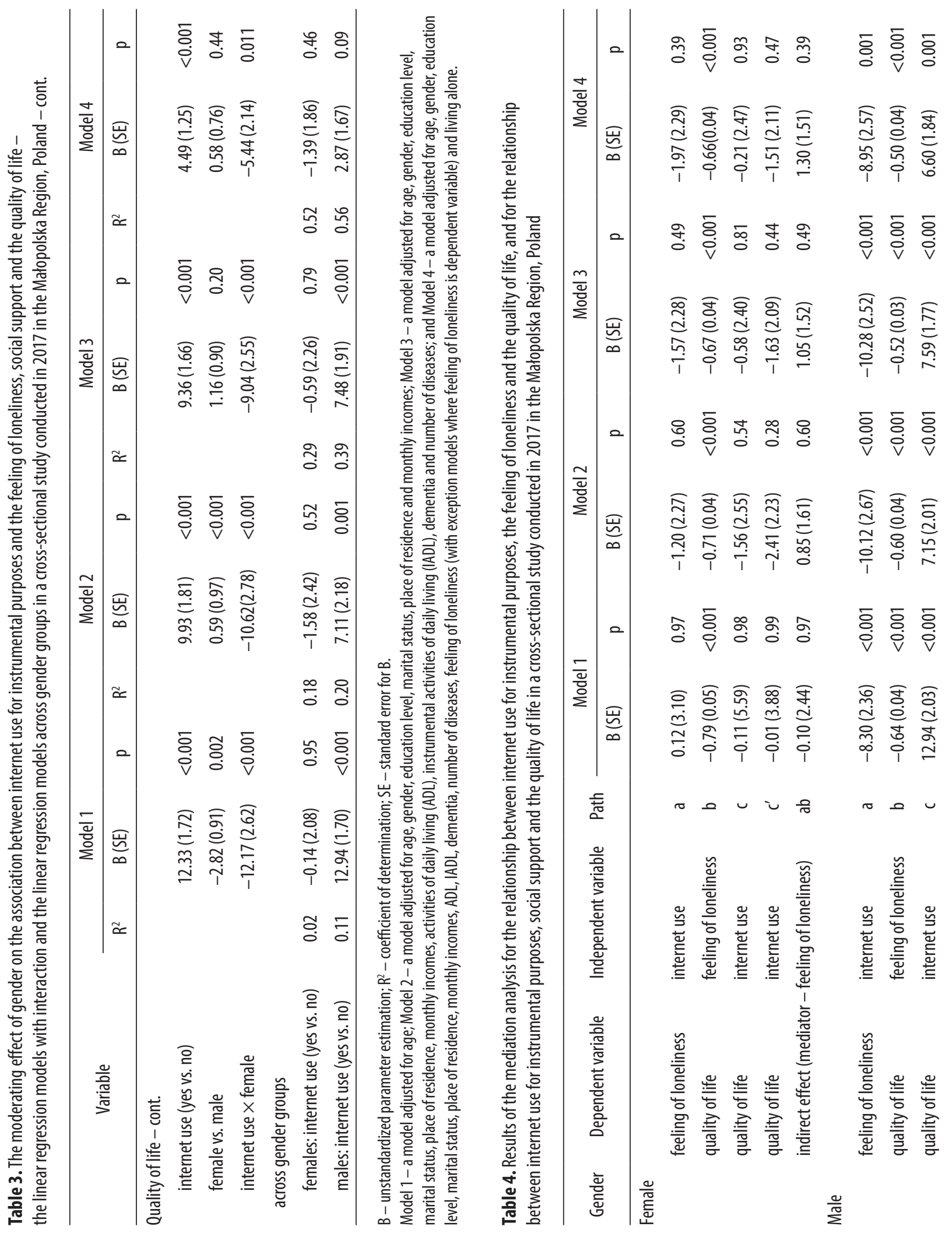




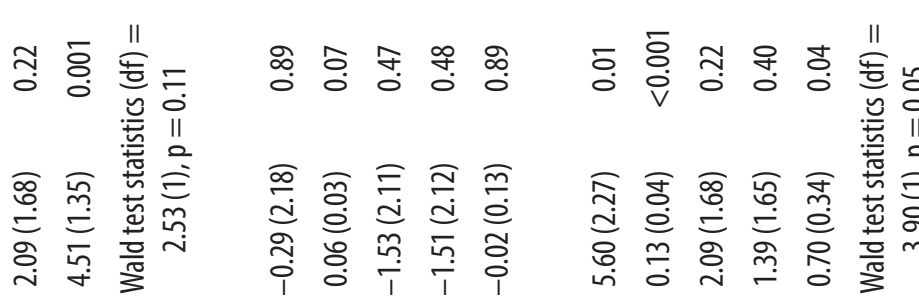

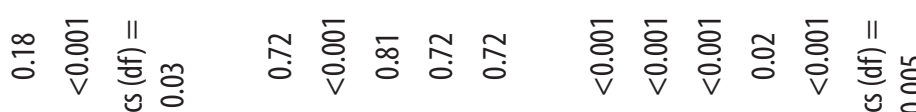

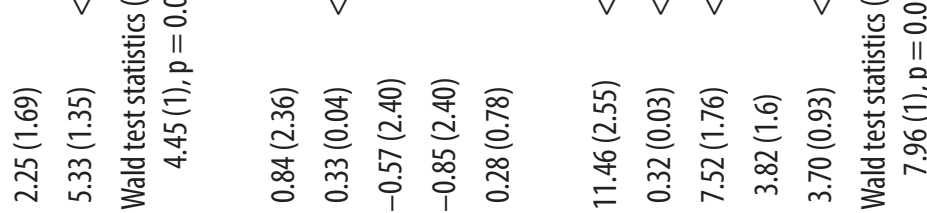

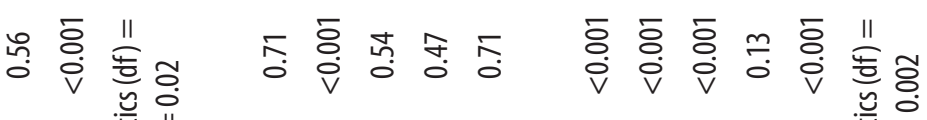
는

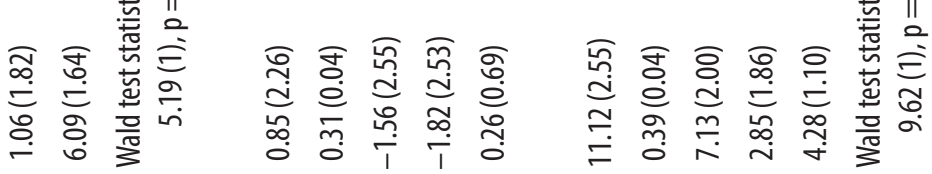

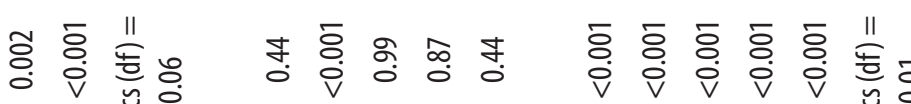

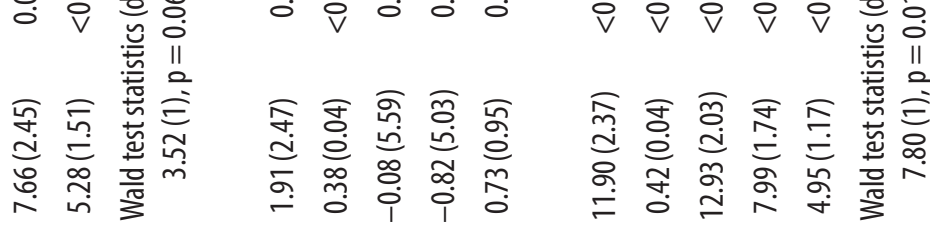

능 응

o

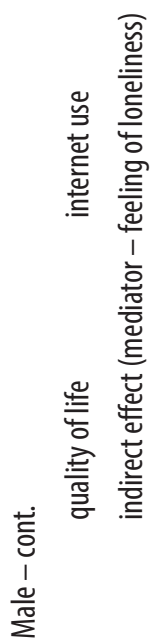

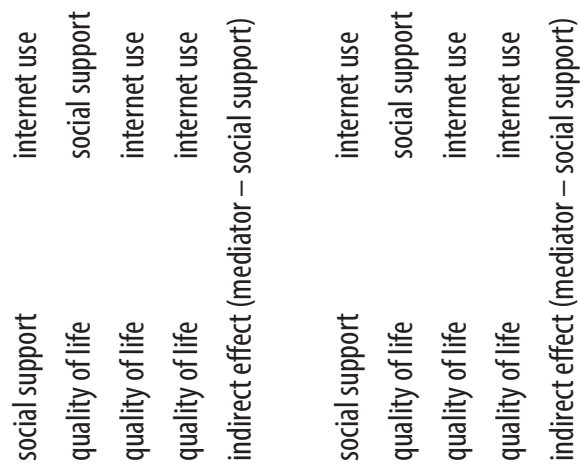

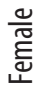

$\frac{0}{20}$

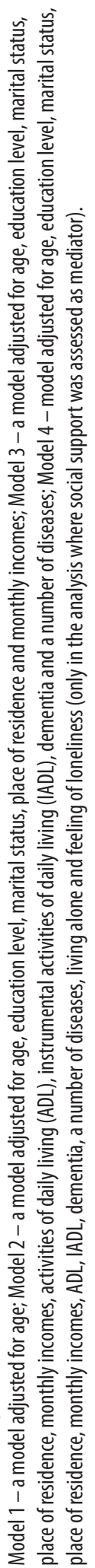



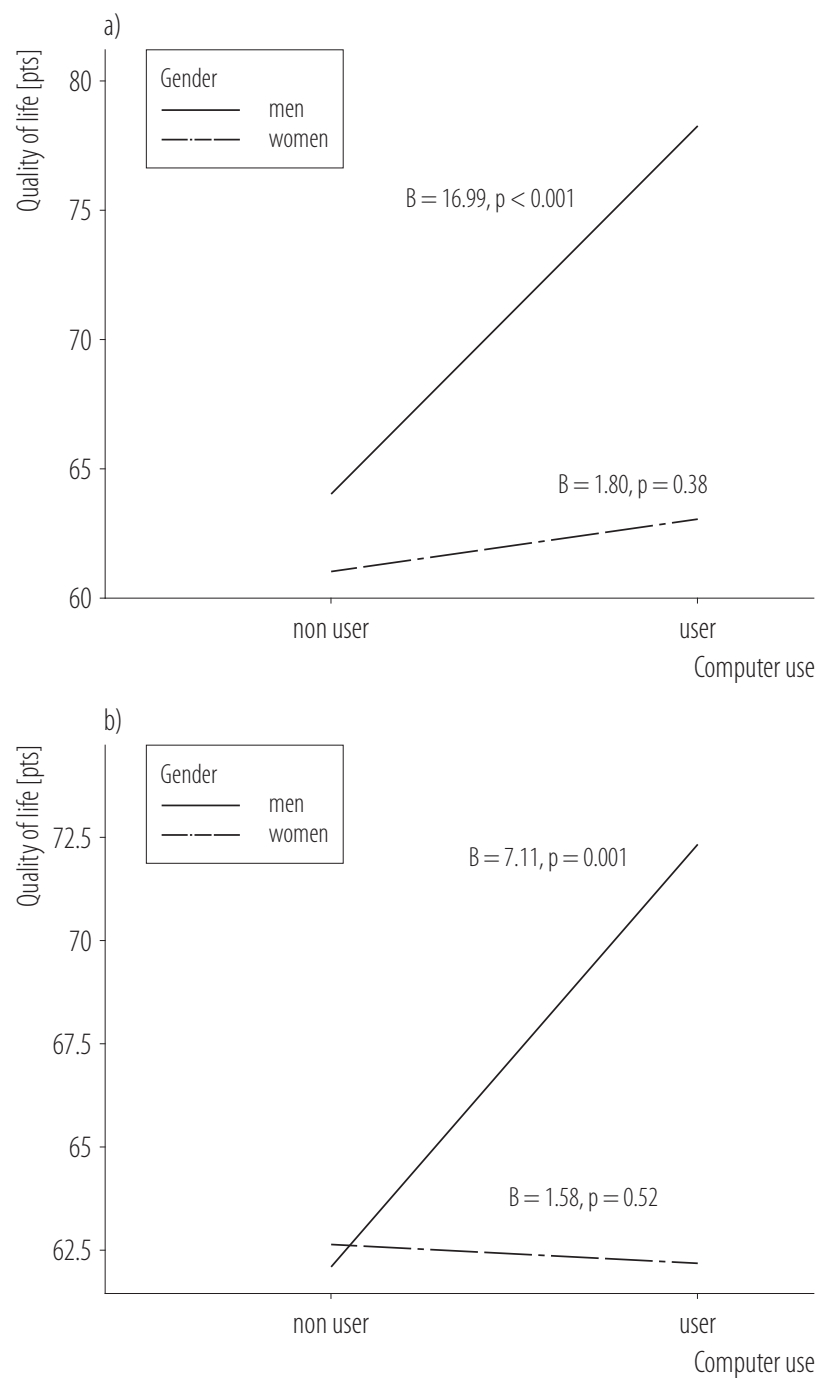

Figure 3. The relationship between internet use for instrumental purposes (computer use) and the quality of life among gender groups: a) model without covariates, b) model 2 (adjusted for age, education level, marital status, place of residence and monthly incomes) in a cross-sectional study among elderly Polish females and males, 2017, the Małopolska Region, Poland

tivities could strengthen their gender identity and make them feel more socially involved and less lonely which, in turn, leads to a better QoL. This result is partly consistent with the research by Sum et al. [18] who stated that using the internet for both entertainment and instrumental purposes was associated with lower levels of social and emotional loneliness among elderly adults.
In addition, these results indicate that social support mediates the relationship between the instrumental use of the internet and the QoL among elderly males. This finding is consistent with a previous study [20] which found that the instrumental use of the internet, such as for financial issues or shopping, was positively related to social engagement in activities, such as volunteering. As has been reported, the younger and more affluent the elderly adults were, the more access they had to ICT devices and the more they used them for instrumental tasks. Referring these results to the findings made in this study, it may be assumed that males, as practical users of ICT, have more financial opportunities to be active in the local environment by taking part, for instance, in different social events and, consequently, gain a possibility to develop supportive relationships which lead them to a better QoL.

In terms of elderly Polish females, the effect of the instrumental use of the internet does not emerge. As it has been found in the previous studies, a greater investment in the maintenance of social ties among elderly women and having more active relations with their kith and kin network affects significantly their emotional functioning [28]. Moreover, as has been mentioned earlier, a higher number of elderly females compared with their male counterparts use the internet for social purposes, such as communicating with friends and family $[16,20]$. Thus, it would be possible that this mode of ICT use could lead to a better QoL among this group. However, as the authors examined internet use for instrumental purposes only, this question cannot be answered.

\section{Strengths and limitations}

It is worth noting that a large randomly selected sample and the possibility of the generalization of results beyond the study sample to the reference population, due to data weighting, should be perceived as strong points of the study. The authors focused separately on elderly females and males which could be considered as a contribution to the cur- 
rent knowledge because most of the existing research concerning this topic treats elderly persons as a homogenous group. Moreover, this research adds to the previous studies by demonstrating that the feeling of loneliness and social support mediate the relationship between the instrumental use of the internet and the QoL in the elderly males group, whereas among elderly females the effect of internet use for instrumental purposes does not occur.

Despite these strengths, some limitations regarding this study should be noted. The first of these is the examination of internet use for instrumental purposes only. Therefore, these findings cannot be referred to the general use of the internet among elderly Polish females and males.

Secondly, the cross-sectional design of the study does not facilitate drawing causal conclusions about the association between internet use for instrumental purposes, loneliness, social support and QoL with regard to the respondents' gender. Thus, all the presented findings should be considered with caution.

Thirdly, a single item was used to measure the internet use level; therefore, in future studies other behavioral characteristics of internet use should be taken into consideration, such as chatting, seeking information, emailing, instant messaging, etc. It is recommended that future studies should also comprise more details about the internet use among elderly adults, such as the purpose of internet use and the types of online activities.

The fourth limitation concerns the limited number of factors of internet use. Future explorations should take into account more technological artifacts such as cell phones and smartphones. In this context, it would be useful to find out, for instance, whether elderly adults use the internet via smartphones.

\section{CONCLUSIONS}

Overall, this study has some implications for the social and healthcare policy and services, suggesting broad interventions to educate and encourage elderly adults to use the internet. However, as was indicated, the elderly population should not be treated as a homogeneous group in terms of internet use. In this context, the "age-based digital divide" [1] could have particularly detrimental effects on the QoL of elderly males for whom, as was shown, internet use for instrumental purposes is associated with a better QoL. This issue turns out to be even more important in the post-pandemic era of COVID-19 which could lead to the greater than previously social isolation of elderly people around the world.

\section{REFERENCES}

1. Gardner PJ, Kamber T, Netherland J. Getting turned on: using ICT to promote active aging in New York City. J Community Inf. 2012;8(1), https://doi.org/10.15353/joci.v8i1.3057.

2. Ramón-Jerónimo MA, Peral-Peral B, Arenas-Gaitán J. Elderly Persons and internet Use. Soc Sci Comput Rev. 2013;31(4):389403, https://doi.org/10.1177/0894439312473421.

3. United Nations [Internet]. World Population Prospects 2019: Highlights; 2019 [cited 2019 June 17]. Available from: https://www.un.org/en/desa/world-population-prospects2019-highlights.

4. Statistics Poland [Internet]. [Quality of Life Among Older People in Poland. Based Upon the Results of Survey of Social Coherence 2015]; 2017 [cited 2017 May 8]. Available from: https://stat.gov.pl/obszary-tematyczne/warunki-zycia/ dochody-wydatki-i-warunki-zycia-ludnosci/jakosc-zyciaosob-starszych-w-polsce,26,1.html. Polish.

5. Hepp A, Krotz F. Mediatized worlds: culture and society in a media age. Basingstoke: Palgrave Macmillan; 2014.

6. Olson KE, O'Brien MA, Rogers WA, Charness N. Diffusion of technology: frequency of use for younger and older adults. Ageing Int. 2011;36:123-45, https://doi.org/10.1007/s12126010-9077-9.

7. Ricardo-Barreto C, Cervantes M, Valencia J, Cano-Barrios J, Mizuno-Haydar J. Colombian Elders and Their Use of Handheld Digital Devices. Front Psychol. 2018;9, https://doi.org/ 10.3389/fpsyg.2018.02009. 
8. Seifert A, Doh M, Wahl H-W. They also do it: internet use by older adults living in residential care facilities. Educ Gerontol. 2017;9:451-61, https://doi.org/10.1080/03601277.2017. 1326224.

9. The WHOQoL Group. Study protocol for the World Health Organization project to develop a Quality of Life assessment instrument (WHOQOL). Qual Life Res. 1993;2(2):153-9, https://doi.org/10.1007/BF00435734.

10. Shapira N, Barak A, Gal I. Promoting older adults' well-being through internet training and use. Aging Ment Health. 2007;11(5):477-84, https://doi.org/10.1080/136078606010 86546.

11. Heo J, Chun S, Lee S, Lee KH, Kim J. Internet use and wellbeing in older adults. Cyberpsych Beh Soc N. 2015;18:26872, https://doi.org/10.1089/cyber.2014.0549.

12. Erickson J, Johnson MG. Internet Use and Psychological Wellness during Late Adulthood. Can J Aging. 2011;30(2): 197-209, https://doi.org/10.1017/S0714980811000109.

13. Elliot AJ, Mooney CJ, Douthit KZ, Lynch MF. Predictors of older adults' technology use and its relationship to depressive symptoms and well-being. J Gerontol B-Psychol. 2014; 69(5):667-77, https://doi.org/10.1093/geronb/gbt109.

14. Zheng R, Spears J, Luptak M, Wilby F. Understanding older adults' perceptions of internet use: An exploratory factor analysis. Educ Gerontol. 2015;41(7):504-18, https://doi. org/10.1080/03601277.2014.1003495.

15. Campbell WS, Kwak N. Mobile Communication and Civic Life: Linking Patterns of Use to Civic and Political Engagement. J Commun. 2010;60(3):536-55, https://doi.org/10. 1111/j.1460-2466.2010.01496.x.

16. Van Boekel LC, Peek ST, Luijkx KG. Diversity in older adults' use of the internet: Identifying subgroups through latent class analysis. J Med Internet Res. 2017;19(5), https:// doi.org/10.2196/jmir.6853.

17. Khalaila R, Vitman-Schorr A. Internet use, social networks, loneliness, and quality of life among adults aged 50 and older: mediating and moderating effects. Qual Life Res. 2018; 27:479-89, https://doi.org/10.1007/s11136-017-1749-4.
18. Sum S, Mathews RM, Hughes I, Campbell A. Internet use and loneliness in older adults. Cyberpsychol Behav. 2008;11(2):208-11, https://doi.org/10.1089/cpb.2007.0010.

19. Tobiasz-Adamczyk B, Galas A, Zawisza K, Chatterji S, Haro MJ, Ayuso-Mateos JL, et al. Gender-related differences in the multi-pathway efect of social determinants on quality of life in older age - the COURAGE in Europe project. Qual Life Res. 2017;26:1865-78, https://doi.org/10.1007/s11136017-1530-8.

20. Ihm J, Hsieh Y P. The implications of information and communication technology use for the social wellbeing of older adults. Inform Commun Soc. 2015;18(10):1123-38, https:// doi.org/10.1080/1369118X.2015.1019912.

21. Choi NG, DiNitto DM. Internet use among older adults: Association with health needs, psychological capital, and social capital. J Med Internet Res. 2013;15(5), https://doi.org/ 10.2196/jmir.2333.

22. Power M, Quinn K, Schmidt S. Development of the WHOQOL-old module. Qual Life Res. 2005;14(10):2197-214, https://doi.org/10.1007/s11136-005-7380-9.

23. Zawisza K, Gałaś A, Tobiasz-Adamczyk B. [Validation of the Polish version of the WHOQOLAGE scale in older population]. Gerontol Pol. 2016;24(1):7-16. Polish.

24. De Jong Gierveld J, Van Tilburg TG. Manual of the Loneliness Scale. Amsterdam: VU University Press; 1999.

25. Dalgard OS, Dowrick C, Lehtinen V, Vazquez-Barquero JL, Casey P, Wilkinson G, et al. Negative life events, social support and gender difference in depression: a multinational community survey with data from the ODIN study. Soc Psychiatr Psychiat Epidemiol. 2006;41(6):444-51, https:// doi.org/10.1007/s00127-006-0051-5.

26. Katz S, Down TD, Cash HR, Grotz RC. Progress in the development of the index of ADL. Gerontologist. 1970;10(1): 20-30, https://doi.org/10.1093/geront/10.1_Part_1.20.

27. Lawton MP, Brody EM. Assessment of older people: Selfmaintaining and instrumental activities of daily living. Gerontologist. 1969;9:179-86, https://doi.org/10.1093/geront/ 9.3_Part_1.179. 
28. Helsper EJ. Gendered Internet use across generations and life stages. Commun Res. 2010;37(3):352-74, https://doi. org/10.1177/0093650209356439.

29. Meadows R, Davidson K. Maintaining Manliness in Later Life: Hegemonic Masculinities and Emphasized Femininities. In: Calasanti MT, Slevin FK, editors. Age Matters. Realigning
Feminist Thinking. New York and London: Routledge; 2006, p. 295-312.

30. Chen YRR, Schulz PJ. The effect of information communication technology interventions on reducing social isolation in the elderly: A systematic review. J Med Internet Res. 2016;18:1-11, https://doi.org/10.2196/jmir.4596.

This work is available in Open Access model and licensed under a Creative Commons Attribution-NonCommercial 3.0 Poland License - http://creativecommons.org/ licenses/by-nc/3.0/pl/deed.en. 